\title{
Stray Current Affects the Release of Bound Chloride Ions in Hydrated Cement Paste
}

\author{
Chonggen Pan ${ }^{1}$, Jian Geng ${ }^{1 *}$, Qingjun Ding ${ }^{2}$ \\ ${ }^{1}$ Research Center of Green Building Materials and Waste Resources Reuse, Ningbo Institute of \\ Technology, Zhejiang University, China \\ ${ }^{2}$ School of Materials Science and Engineering, Wuhan University of Technology, China \\ *E-mail: gengjian@whut.edu.cn
}

doi: $10.20964 / 2018.06 .77$

Received: 17 January 2018 / Accepted: 12 March 2018 / Published: 10 May 2018

\begin{abstract}
Here, the effect of stray current on the release of bound chloride ions was evaluated using applied direct current (DC). Stray current induced the release of bound chloride ions, which escalated with both increasing loading time and voltage. The release of bound chloride ions in hydrated cement paste (HCP) was attributed to the release of chloride ions that had been adsorbed by the C-S-H gel. Owing to their attraction in the stray current's electrical field, adsorbed chloride ions in the electrical double layer(EDL) of the C-S-H gel—including both Stern and diffusion layers-were released. This also resulted in an increased zeta potential $(\zeta)$ of the C-S-H gel surface. Since the EDL thickness will gradually thin due to the stray current's electrical field, the amount of chloride ions re-entering the EDL will decrease after the stray current is stopped. Given this, there is a long-term, negative effect of stray current on the stability of bound chloride ions in hydrated cement paste.
\end{abstract}

Keywords: Stray current; Bound chlorides; C-S-H gel; Electrical double layer; Zeta potential

\section{FULL TEXT}

(C) 2018 The Authors. Published by ESG (www.electrochemsci.org). This article is an open access article distributed under the terms and conditions of the Creative Commons Attribution license (http://creativecommons.org/licenses/by/4.0/). 